\title{
Anaphylaxis to Glatiramer Acetate
}

\author{
By Stefan Wöhrl", Felix Wantke and Wolfgang Hemmer
}

\author{
Floridsdorf Allergy Centre (FAZ), Franz-Jonas-Platz 8/6, A-1210 Vienna, Austria
}

\begin{abstract}
Glatiramer acetate (Copaxone, Teva Pharma) and interferon beta are the two only disease-modifying therapies for multiple sclerosis. Glatiramer acetate is known for frequently simulating mild, anaphylactoid reactions while true, IgEmediated allergic reactions have been hardly reported so far. Herein, we report two females suffering from multiple sclerosis who experienced rapidly aggravating hypersensitivity-reactions upon treatment with glatiramer acetate. Patient one experienced an asthma attack, patient two an exacerbation of her urticaria and angioedema. An IgE-mediated mechanism could be demonstrated by a positive intradermal test to a 1:1000 dilution in the first 31-year old and by a positive skin prick test to a 1:10 diluted skin prick test in the second 32-year old second woman.
\end{abstract}

Keywords: Adverse drug reaction, Drug anaphylaxis, Drug hypersensitivity reaction (DHR), Drug allergy, Glatiramer acetate, Multiple sclerosis treatment, Side effect.

\section{INTRODUCTION}

Currently, interferon beta and glatiramer acetate (GA, Copaxone ${ }^{\circledR}$, Teva Pharma, Utrecht, The Netherlands) are the only disease modifying therapies for multiple sclerosis (MS), an inflammatory, relapsing, autoimmune disease of the central nervous system [1]. GA is a mixture of 4 synthetic peptides composed of the 4 left-handed amino acids alanine, glutamic acid, lysine, and tyrosine [2]. Subcutaneously applied GA is known for its' mast cell stimulating capacity leading to injection site reactions that are usually self-limited [2]. Rarely, subcutaneous GA can lead to mild anaphylactoid reactions. Hence, differentiating these anaphylactoid "immediate postinjection systemic reactions (IPISR)" [3] from true allergic, IgE-mediated reactions is difficult [4]. IgE-mediated reactions have been hardly reported so far. Herein, we report two female MS patients presenting with anaphylaxis after the application of GA.

\section{REPORT OF TWO CASES}

\section{Case 1}

A 31 year-old woman had been diagnosed with MS in July 2011. She was put on Interferon Beta (Avonex ${ }^{\circledR}$, Biogen Idec, Hillerod, Denmark; 6 Mio U 3 times / week) and completely recovered from her hemiplegia of the upper extremities. However, although under premedication with $400 \mathrm{mg}$ Dexibuprofen (Seractil®, Gebro Pharma, Fieberbrunn, Austria) the Interferon-specific side effects such as chills, headache and malaise could never be controlled sufficiently. To make matters worse, she also developed depression, a condition aggravated by IFN therapy. When she experienced a

*Address correspondence to this author at the Floridsdorf Allergy Centre (FAZ), Franz-Jonas-Platz 8/6, A-1210 Vienna, Austria;

Tel: +43-1-2702541-0; Fax: +43-1-2702542-78; Email: woehrl@faz.at relapse of her MS in November 2013, her neurologist switched her from IFN to daily GA $20 \mathrm{mg}$ subcutaneously. The relapse was controlled quickly under this treatment. However, already after a few GA applications the patient developed localized urticarial lesions around the injection site. Her neurologist kept her on GA despite systemic reactions aggravating with each injection. The eleventh injection culminated in a grade III systemic reaction consisting of urticaria and severe shortness of breath requiring emergency intervention within less than five minutes after the application of GA.

Afterwards, the patient was referred to our allergy clinic (February 2014). A standard allergy workup consisting in skin prick testing (SPT) to inhalant and food allergens, assessment of total IgE, serum tryptase and lung function revealed no abnormalities. SPT with diluted $(1: 10=2 \mathrm{mg} / \mathrm{ml})$ and pure GA $(20 \mathrm{mg} / \mathrm{ml})$ remained negative but intradermal testing (IDT) with GA at dilutions of 1:1000 $(=20 \mu \mathrm{g} / \mathrm{ml})$ and 1:100 $(=200 \mu \mathrm{g} / \mathrm{ml})$ resulted in clear immediate reactions (rated as "+" and "++" according to the German skin test guideline [5]) while negative controls with intradermal saline remained negative. The patient was diagnosed as allergic to GA. The neurologist stopped GA and - on her own wish - the patient was switched to a "wait and see" strategy without any specific MS-treatment and still without any sign of relapse up to 6 months after stopping GA.

\section{Case 2}

In March 2014 a 32 year-old female patient presents with a history of increasing local reactions to treatment with GA. She has been suffering from MS for several years. After an initial crisis, her MS was stabilised with GA at the same standard dose as patient \#1. As the patient has been suffering from chronic spontaneous urticarial with angioedema (CSU), drug hypersensitivity reactions were falsely assumed by her neurologist. The neurologist started the long-known 


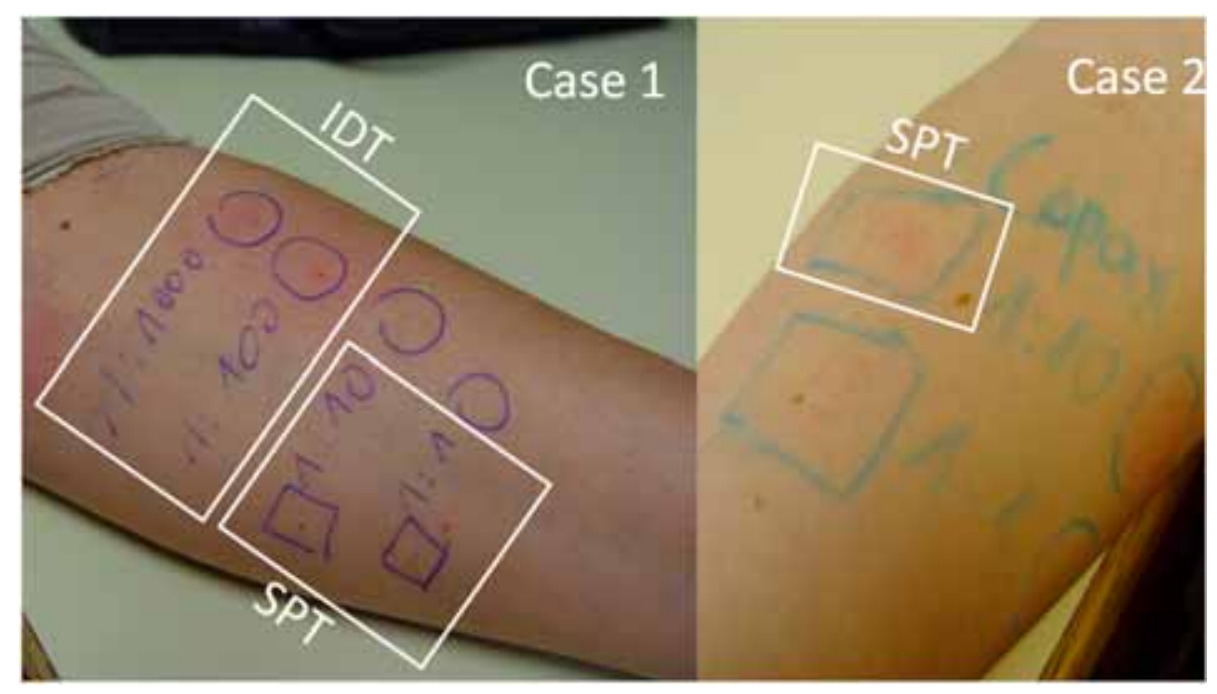

Fig. (1). Left panel (Patient \#1): Positive intradermal tests (IDT) with Copaxone ${ }^{\circledR}$ (Glatiramer acetate, GA) at the dilutions of 1:1000 and 1:100. Skin prick tests (SPT) with 1:10 diluted and undiluted GA remained negative. Apositive histamine control is visible in the cubita ("+"). Negative controls on the opposite arm are not shown.

Right panel (Patient 2): Positive SPT at a dilution of 1:10. Positive and negative controls on the opposite arm are not shown.

Psoriasis drug dimethyl fumarate (DMF; Fumaderm ${ }^{\circledR}$, Biogen Idec, Ismaning, Germany) $120 \mathrm{mg}$ orally four times in a day, which had been recently reported as a second linetherapy for MS [6]. The local injection site reactions and the CSU worsened despite concomitant treatment with oral glucocorticoid. Hence, the neurologist referred the patient to our institution where she presented with a concomitant treatment of GA and DMF and with still uncontrollable CSU.

She showed us an impressive collection of self-taken photographs on her mobile phone helping to easily diagnose CSU. A standard allergy work up including SPT to a standard allergy series, lung function, serum tryptase, and total IgE remained all in the normal range. We also performed SPTs with GA as reported above giving positive results already at a dilution of 1:10 $(2 \mathrm{mg} / \mathrm{ml})$. In a CSU patient, we regarded an SPT as more specific than an IDT. Nevertheless, we additionally performed an IDT at the single dilution of $1: 10(2 \mathrm{mg} / \mathrm{ml})$ that resulted in a (potentially unspecific) strong positive reaction while the control with saline remained negative. The patient documented a persistence of this positive reaction lasting for at least 6 hours on her mobile phone. Overall, we especially considered the SPT as being specific and the patient was diagnosed as being hypersensitive to GA.

GA was stopped in patient number 2 and she remained on DMF to control her MS. The oral corticosteroid could be tapered and a sole therapy with $10 \mathrm{mg}$ oral Levocetirizine (Xyzall@, Aesica, Pianezza, Italy) was sufficient for controlling her CSU. Because of Levoceterizine's sedating side effect, the antihistamine had to be switched to $120 \mathrm{mg}$ Fexofenadine (Allegra ${ }^{\circledR}$, Sanofi-Aventis, Tours, France) a few weeks later. At the time of writing this manuscript a switch to an alternative second line treatment using highdose intravenous immunoglobuline (hdIVIG) was being considered as a possibility for a simultaneous off-label treatment for both conditions: MS [7] and CSU [8].

\section{DISCUSSION}

It is a well-known problem that the reading of skin tests with drugs with mast cell-activating capacities such as nondepolarizing muscle relaxants or opiates is difficult. Differentiating unspecific reactions from true allergic, IgEmediated reactions is hardly possible. Validated, commercially available in vitro tests proving an IgE-mediated mechanism for these drugs are not available and the sensitivity and specificity of non-commercial, self-coupled ELISAs and basophil activation tests for the detection of allergenspecific IgE remains questionable. While negative skin tests are usually helpful in the clinical management of these patients, the specificity of positive skin tests always remains doubtful. GA should be considered as another candidate of this group.

Hence, the specificity of the positive skin tests in our patients and the question, if these results were really a prove for an IgE-mediated mechanism, remains uncertain. Two independent observations may support the specificity of the positive skin tests:

1 In both patients, the reactions gradually progressed from local injection-site reactions in the beginning to more pronounced, systemic reactions (urticaria and angioedema in patient \#2 and severe asthma attacks in patient \#1). This suggests an evolving immunological mechanism instead of a direct, unspecific mast-cell activating effect that should have remained at the same intensity over time and should have occurred from the very beginning. These gradually worsening conditions had already been described by Baumgartner et al. [3] and GA-specific IgE had been found on several occasions before $[2,4]$. Still, the allergen in Copaxone ${ }^{\circledR}$ is not well defined yet. On the one hand, the peptides themselves and a cross-reaction to the human myelin basic protein may serve as the antigen [9] while, on the other hand, some authors argue that the solvent mannitol might also play a minor role [3]. 
2 Non-irritating concentrations for skin tests have only been reported for a few drugs so far [10] but not for GA. Rauschka et al. [4], Sanchéz-López et al. [11] and Soriano-Gomiz [2] considered in their reports on one, three and three patients, respectively, a positive reaction in IDTs from a dilution of 1:100 $(\leq 0.2$ $\mathrm{mg} / \mathrm{ml}$ ) and Soriano-Gomiz and Corominas et al. [9] an SPT to undiluted GA in one and three patients, respectively, as specific. This was the case in both of our patients. A single recent case report now claims, that only higher dilutions of GA of up to $1: 1.000,000$ $(=0.02 \mu \mathrm{g} / \mathrm{ml})$ should be regarded as specific [12] contradicting all the other publications $[2,9,11]$. We believe, that such an unusual high dilution is not in line with the common 1:10 or 1:100 dilutions recommended by ENDA/EAACI in their recent publication on non-irritating skin test concentrations for systemically applied drugs [10].

The MS of both patients is currently controlled differently. While patient \#1 at present is asymptomatic without MS-specific therapy, the MS of patient \#2 is currently controlled with DMF. High dose immunoglobulin could be another possibility especially for patient \#2 as already mentioned above. If GA should ever have to be re-introduced because of a lack of other neurologic treatment options, a successful desensitization protocol to GA has already been published $[12,13]$.

In summary, we report anaphylaxis to GA in two cases of relapsing multiple sclerosis. Due to the irritating potential of subcutaneously applied GA, the specificities of positive skin tests to GA have to be judged critically in each individual case.

$$
\begin{aligned}
& \text { ABBREVIATIONS } \\
& \text { DMF }=\text { Dimethyl Fumarate } \\
& \text { GA }=\text { Glatiramer Acetate } \\
& \mathrm{IDT}=\text { intradermal test } \\
& \mathrm{IFN}=\text { Interferon } \\
& \mathrm{SPT}=\text { skin prick test }
\end{aligned}
$$

\section{ACKNOWLEDGEMENTS}

Declared none.

\section{REFERENCES}

[1] Caporro M, Disanto G, Gobbi C, Zecca C. Two decades of subcutaneous glatiramer acetate injection: current role of the standard dose, and new high-dose low-frequency glatiramer acetate in relapsing-remitting multiple sclerosis treatment. Patient Prefer Adherence 2014; 8: 1123-34.

[2] Gomis VS, Sempere AP, Delgado PG, et al. Glatiramer acetate anaphylaxis: detection of antibodies and basophil activation test. J Investig Allergol Clin Immunol 2012; 22(1): 65-6.

[3] Baumgartner A, Stich O, Rauer S. Anaphylactic reaction after injection of glatiramer acetate (copaxone $®)$ in patients with relapsing-remitting multiple sclerosis. Eur Neurol 2011; 66(6): 368-70.

[4] Rauschka H, Farina C, Sator P, et al. Severe anaphylactic reaction to glatiramer acetate with specific IgE. Neurology 2005; 64(8): 1481-2.

[5] Ruëff F, Bergmann K-C, Brockow K, et al. Hauttests zur Diagnostik von allergischen Soforttypreaktionen. Allergo J 2010; 19: 402-15.

[6] Gold R, Kappos L, Arnold DL, et al. Placebo-controlled phase 3 study of oral bg-12 for relapsing multiple sclerosis. New Engl J Med 2012; 367(12): 1098-107.

[7] Nickerson M, Marrie RA. The multiple sclerosis relapse experience: patient-reported outcomes from the North American Research Committee on Multiple Sclerosis (NARCOMS) Registry. BMC Neurol 2013; 13: 119.

[8] Jandus P, Hausmann O, Pichler WJ, Helbling A. Intravenous immunoglobulin in urticaria. J Investig Allergol Clin Immunol 2013; 23(1): 71-3.

[9] Corominas M, Postigo I, Cardona V, et al. IgE-mediated allergic reactions after the first administration of glatiramer acetate in patients with multiple sclerosis. Int Arch Allergy Immunol 2014; 165(4): 244-6.

[10] Brockow K, Garvey LH, Aberer W, et al. Skin test concentrations for systemically administered drugs - an ENDA/EAACI Drug Allergy Interest Group position paper. Allergy 2013; 68(6): 702-12.

[11] Sánchez-López J, Rodriguez del Rio P, Cases-Ortega B, MartinezCócera C,Fernández-Rivas M. Allergy workup in immediate-type local reactions to glatiramer acetate. J Investig Allergol Clin Immunol 2010; 20(6): 521-3.

[12] Crestani E, Lee J, Gorman M, Castells M, Dioun AF. IgE-mediated hypersensitivity reaction and desensitization to glatiramer acetate in a pediatric patient. Pediatr Allergy Immunol 2014; 25(8): 82123.

[13] Bains SN, Hsieh FH, Rensel MR, et al. Glatiramer acetate: successful desensitization for treatment of multiple sclerosis. Ann Allergy Asthma Immunol 2010; 104(4): 321-5.

\section{CONFLICT OF INTEREST}

The author confirms that this article content has no conflict of interest.

Received: December 23, $2014 \quad$ Revised: April 17, 2015

(C) Wöhrl et al.; Licensee Bentham Open.

This is an open access article licensed under the terms of the Creative Commons Attribution Non-Commercial License (http://creativecommons.org/licenses/by-nc/3.0/) which permits unrestricted, non-commercial use, distribution and reproduction in any medium, provided the work is properly cited. 